\title{
FIBT versus florbetaben and PiB: a preclinical comparison study with amyloid-PET in transgenic mice
}

Behrooz H Yousefi ${ }^{*}$, Boris von Reutern ${ }^{2,4}$, Daniela Scherübl ${ }^{2}$, André Manook ${ }^{1,2}$, Markus Schwaiger ${ }^{2}$, Timo Grimmer ${ }^{3}$, Gjermund Henriksen², Stefan Förster ${ }^{2}$, Alexander Drzezga ${ }^{2,5}$ and Hans-Jürgen Wester ${ }^{1}$

\begin{abstract}
Background: Over the last decade, an increasing number of studies have been published on the use of amyloid- $\beta$ (A $\beta$ ) PET imaging with different ${ }^{18} \mathrm{~F}$-radiopharmaceuticals for clinical characterization of Alzheimer's disease (AD) in different stages. However, distinct study cohorts and different quantification techniques allow only for an indirect comparison between the different tracers. Thus, the aim of this study was the direct intra-individual in vivo comparison of different A $\beta$-targeted radiopharmaceuticals for PET imaging, including the newly developed agent $\left[{ }^{18} \mathrm{~F}\right] \mathrm{FIBT}$.

Methods: A small group of four animals of a well-characterized APP/PS1 transgenic (tg) mouse model of AD and gender-matched control (ctl) animals underwent a sequential and standardized PET imaging regimen for direct comparison of $\left[{ }^{18} \mathrm{~F}\right] \mathrm{FIBT}$, $\left[{ }^{18} \mathrm{~F}\right]$ florbetaben, and $\left[{ }^{11} \mathrm{C}\right] \mathrm{PiB}$. The quantitative PET imaging data were cross-validated with the cerebral $A \beta$ plaque load as quantified ex vivo on histological sections.

Results: We found that FIBT (2-(p-methylaminophenyl)-7-(2-[ $\left.{ }^{18} \mathrm{~F}\right]$ fluoroethoxy)imidazo[2,1-b]benzothiazole) compares favorably to florbetaben as a high-contrasting PET radiopharmaceutical for imaging A $\beta$ pathology. The excellent pharmacokinetics of FIBT in combination with its high-binding affinity towards $A \beta$ resulted in feasible high-contrast imaging of $A \beta$ with high global cortex to cerebellum standard uptake value ratio (SUVR) in 24-month-old tg mice ( $\operatorname{tg} 1.68 \pm 0.15$ vs. ctl $0.95 \pm 0.02$ ). The SUVRs in transgenic versus control animals ( $\left.S U V R_{t g} / S U V R_{c t}\right)$ for FIBT $(1.78 \pm 0.16)$ were similar to the ratios as observed in humans $\left(S \cup \vee R_{A D} / S \cup V R_{c t 1}\right)$ for the established gold standard Pittsburgh compound B (PiB) $(1.65 \pm 0.41)$.

Conclusions: This head-to-head PET tracer comparison study in mice indicated the good imaging properties of $\left[{ }^{18} \mathrm{~F}\right] \mathrm{FIBT}$, such as high initial brain uptake, fast clearance of the brain, and high binding affinity towards $A \beta$ as directly compared to the established amyloid tracers. Moreover, the preclinical study design is recommendable for reliable assessment and comparison of novel radiopharmaceuticals.
\end{abstract}

Keywords: Alzheimer's disease; $\beta$-amyloid; Small-animal PET; In vivo radiotracers ranking; FIBT; Florbetaben; PiB; APP/PS1 transgenic mouse animal model of AD; In vivo imaging; Autoradiography

\section{Background}

Amyloid- $\beta$ (A $\beta)$ PET has become an important research biomarker for diagnosing and differentiating neurodegenerative disorders, in particular Alzheimer's disease (AD). In the last decade, major efforts to develop and assess radiopharmaceuticals for early visualization and

\footnotetext{
* Correspondence: b.yousefi@tum.de

'Department of Pharmaceutical Radiochemistry, Technische Universität München, Walther-Meißner-Str. 3, 85748 Garching, Germany Full list of author information is available at the end of the article
}

quantification of $\mathrm{A} \beta$ deposits with PET have been reported [1-3]. These endeavors were related to the amyloid cascade hypothesis which assumes that fibril$\operatorname{lar} \mathrm{A} \beta$ is one of the key pathogenic hallmarks of $\mathrm{AD}$ [4-6], therefore, it has been depicted as major target for non-invasive diagnosing of AD. They have resulted in a variety of newly developed radiopharmaceuticals which have been assessed in preclinical and clinical studies [7-10]. Currently, three ${ }^{18}$ F-labeled PET radiopharmaceuticals for $A \beta$ have been evaluated in clinical 
studies and are now approved by the United States Food and Drug Administration (FDA) and by the European Medicines Agency (EMA): flutemetamol [11,12], florbetaben [13-15], and florbetapir [16-24]. At least two other tracers are already undergoing clinical investigation $[25,26]$. In our lab, a new series of $A \beta$ ligands, imidazo[2,1-b]benzothiazole (IBT), has been developed inspired by positive imaging results obtained in the IMPY and Pittsburgh compound B (PiB) studies. The IBT structural motifs share features with IMPY and $\mathrm{PiB}$. Furthermore, it also allows stable ${ }^{18} \mathrm{~F}$-fluorination. Our aim was to develop a more sensitive $A \beta$ ligand that is easy to synthesize and therefore allows early and practicable detection of amyloid deposition [25,27,28]. With several ${ }^{18} \mathrm{~F}$-labeled tracers competing, comparative conclusions are of high interest. However, most of the published studies so far have relied on different methodologies and cohorts, and a direct comparison and ranking in a clinical setting is challenging for their different characteristics [29]. These limitations draw the attention to preclinical approaches for a direct intra-individual in vivo comparison of different ${ }^{18} \mathrm{~F}$-labeled $\mathrm{A} \beta$ tracers.

Alongside tracer development advances subsequent to the application of PiB in a clinical setting [30], A $\beta$ PET imaging was advanced with more sophisticated detection modes and highly sensitive detectors combined with powerful reconstruction and quantification algorithms [31]. In addition, several transgenic animal models of AD have been established for preclinical evaluation of experimental treatments [32-34,10]. A $\beta$ PET imaging in transgenic mouse models of $\mathrm{AD}$ is a powerful tool to assess $A \beta$ tracer properties in vivo [27,35-38]. However, recent publications made it clear that the type of mouse model seems to play a crucial role as they differ in extent and type of $A \beta$ pathology [39,35]. A new APP/PS1 transgenic mouse model of AD, expresses mutant forms of human amyloid precursor protein (APP) and presenilin-1 (PS1), was characterized [33] in collaboration with our group for its application in $A \beta$ imaging [40] and usage for the evaluation of new $A \beta$ ligands $[25,27,40]$. For this mouse model, a linear relationship of $A \beta$ plaque pathology and PiB PET signal was observed [41].

In the current study, we employed this APP/PS1 mouse model for a direct comparison of two established and one newly developed A $\beta$ PET tracer (Scheme 1 ). Among the
${ }^{18}$ F-labeled A $\beta$ PET radiopharmaceuticals, $\left[{ }^{18} \mathrm{~F}\right]$ florbetaben has shown good sensitivity and specificity for the detection of $\mathrm{AD}$ [42]. Hence, $\left[{ }^{18} \mathrm{~F}\right]$ florbetaben was selected as reference ${ }^{18} \mathrm{~F}$-radiopharmaceutical and compared with a promising in-house developed $\mathrm{A} \beta$ PET tracer $\left[{ }^{18} \mathrm{~F}\right] \mathrm{FIBT}[25,27]$ and the ${ }^{11} \mathrm{C}$-labeled gold standard $\left[{ }^{11} \mathrm{C}\right] \mathrm{PiB}$. In vivo small animal PET imaging and ex vivo validation experiments were carried out for ranking the tracers.

In order to estimate the translational value of the preclinical results, we compared $\left[{ }^{11} \mathrm{C}\right] \mathrm{PiB}$ standard uptake value ratio (SUVR) values from our APP/PS1 and control mice with human $\left[{ }^{11} \mathrm{C}\right] \mathrm{PiB}$ SUVR values from $20 \mathrm{AD}$ patients and 15 healthy elderly volunteers.

\section{Methods}

\section{Animals}

Animal experiments were carried out with the approval of the institutional animal care committee (Regierung von Oberbayern, München, Germany) and in accordance with the German Animal Welfare Act. Animal husbandry followed the regulations of the European Union (EU) guideline no. 2010/63. All imaging experiments were performed with male mice: four homozygous APP/PS1 mice ((B6;CB-Tg(Thy1-Psen1*M146V/Thy1-APP*swe)-10Arte), TaconicArtemis $\mathrm{GmbH}$, Cologne, Germany) on a congenic C57BL/6 J genetic background and three age-matched control mice (C57BL/6 J). Mean age and mean weight: $23.8 \pm$ 0.4 months and $33.3 \pm 3.2$ for APP/PS1 mice $(\mathrm{tg})$ and $24.6 \pm$ 0.4 months and $38.8 \pm 2.6 \mathrm{~g}$ for $\mathrm{C} 57 \mathrm{BL} / 6 \mathrm{~J}$ control mice (ctl), respectively. For biodistribution studies, BALB/c mice were obtained from Charles River Laboratories, Sulzfeld, Germany.

\section{Human subjects}

Human data comes from preexisting studies at the Department of Nuclear Medicine with subjects who were recruited from the outpatient memory clinic of the Department of Psychiatry at the Technische Universität München (TUM). They had been referred for the diagnostic evaluation of cognitive impairment by general practitioners, neurologists, psychiatrists, or from other institutions. They underwent a standardized diagnostic protocol. All examinations were part of their routine check-up in the course of the evaluation of the patient's neurodegenerative disorders. The psychometric workup was based on the Consortium to Establish a

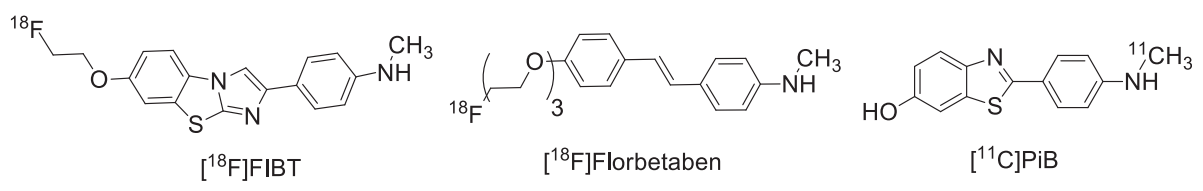

Scheme 1 Chemical structure of the three $A \beta$ radiopharmaceuticals used in this study. 
Registry for AD (CERAD) neuropsychological battery, which includes the Mini-Mental-State Examination (MMSE). All patients provided a written informed consent regarding the scientific evaluation of their data.

\section{Radiosynthesis}

All chemicals, solvents, and materials were purchased and directly used without further purification. $\left[{ }^{18} \mathrm{~F}\right]$ florbetaben $(8 \% \pm 2 \%$ radiochemical yield (RCY) and $98 \%$ radiochemical purity) $[43,44],\left[{ }^{18} \mathrm{~F}\right] \mathrm{FIBT}(20 \% \pm 4 \% \mathrm{RCY}$ and $98 \%$ radiochemical purity) [25], and $\left[{ }^{11} \mathrm{C}\right] \mathrm{PiB}(26 \%$ $\pm 5 \%$ RCY and $98 \%$ radiochemical purity) [45-47,27] were synthesized following already published procedures. Analytical HPLC was performed using either a Chromolith RP-C18e $(4.6 \times 100$ mm; Merck, Dramstadt, Germany) eluted with a mixture of acetonitrile/0.1-M ammonium formate (MeCN content between $27.5 \%$ and $50 \%$ ) at a flow rate of $5 \mathrm{~mL} / \mathrm{min}$ or a Nucleosil $100, \mathrm{CN}$ $4.6 \times 250 \mathrm{~mm}$ reverse phase column, particle size $5 \mu \mathrm{m}$ (CS-Chromatographie, Langerwehe, Germany) eluted with acetonitrile/0.1-M ammonium formate (MeCN content between $40 \%$ and 60\%). Both chromatography systems were fitted with a UV detector (Sykam Model S3210 set at $254 \mathrm{~nm}$; Sykam, Fürstenfeldbruck, Germany). Radiotracers had comparable specific activities of $\geq 18 \mathrm{GBq} / \mu \mathrm{mol}$.

\section{Lipophilicity (log $\left.D_{\text {oct/PBS }}\right)$ measurements}

Lipophilicity of the employed compounds was determined by a conventional partition method between 1octanol and phosphate buffered saline (PBS), pH 7.4. The 1-octanol was saturated with PBS before use. Briefly, the no-carrier-added tracers, contained in $0.2 \mathrm{~mL}$ PBS, were added $0.2 \mathrm{~mL}$ of 1 -octanol in a 1.5 $\mathrm{mL}$ polypropylene Eppendorf vial. The vial was sealed and vigorously shaken at room temperature for $5 \mathrm{~min}$. The mixture was then centrifuged at $3,000 \mathrm{~g}$ for $10 \mathrm{~min}$. A $100 \mu \mathrm{L}$ aliquot from each of the two phases was drawn and their radioactivity content was determined in a NaI (Tl) well-type detector. The $\log D_{\text {oct/PBS }}$ was calculated as follows: $\log D_{\text {oct } / \mathrm{PBS}}=\log$ (radioactivity concentration in the 1-octanol phase/radioactivity concentration in the PBS phase). The reported values represent the mean of six independent measurements.

\section{Brain uptake studies of FIBT, florbetaben, and PiB in BALB/c mice}

Ex vivo brain uptake studies were performed in male $\mathrm{BALB} / \mathrm{c}$ mice (mean \pm SD body weight: $23 \pm 2 \mathrm{~g}$ ). Mice were injected via lateral tail vein with 4 to $6 \mathrm{MBq}$ of high specific activity $(\geq 11 \mathrm{GBq} / \mu \mathrm{mol}) \quad\left[{ }^{18} \mathrm{~F}\right] \mathrm{FIBT}$, $\left[{ }^{18} \mathrm{~F}\right]$ florbetaben, and $\left[{ }^{11} \mathrm{C}\right] \mathrm{PiB}$ contained in 0.1 to $0.15 \mathrm{~mL}$ of a solution of isotonic phosphate buffered saline. Groups of mice were killed at 5 and $30 \mathrm{~min}$ p.i.
Radioactivity of weighted brain samples was measured in a $\gamma$-counter (Wallac 1480-011 Automatic Gamma Counter, PerkinElmer, Waltham, MA, USA). Data are expressed as percent of the injected dose per gram tissue (\% I.D./g; mean $\pm \mathrm{SD}, N=5$ ).

\section{PET imaging}

\section{Small animal PET}

Inhalation anesthesia with isoflurane was used and the eyes of the animals were protected with dexpanthenol eye ointment. Anesthesia was initiated $15 \mathrm{~min}$ ahead of experiments by placing the animal in a cage ventilated with oxygen $(3.5 \mathrm{~L} / \mathrm{min})$ containing $3 \%$ isoflurane. Throughout the experiments, anesthesia was maintained by adjusting the isoflurane content $(0.6 \%$ to $2 \%)$ to ensure a respiratory rate in the range 80 to $100 / \mathrm{min}$. For i.v. injection, we inserted a tailored catheter into the lateral tail vein. Simultaneously with a slow bolus injection of 50 to $200 \mu \mathrm{L}$ of tracer solution, we started the PET with scan duration of $45 \mathrm{~min}$ in 3D list mode on a Siemens Inveon system (axial field-of-view of $12.7 \mathrm{~cm}$ with a bore diameter of $12 \mathrm{~cm}$, approximately $1.4 \mathrm{~mm}$ fullwidth-at-half-maximum spatial resolution; Siemens Healthcare, Erlangen, Germany). After tracer injection, we flushed the catheter with 50 to $100 \mu \mathrm{L}$ of isotonic sodium chloride solution. During the scan, a heating pad prevented hypothermia. The radioactivity in the syringe was measured immediately before and after injection with a Capintec CRC ${ }^{\ominus}$ 15R (Capintec Inc, 6 Arrow Road Ramsey, NJ, USA) dose calibrator.

\section{Scanning regimen of PiB, FIBT, and florbetaben}

Measurements of all three tracers in each animal were performed within a time period of 16 days to guarantee for comparable underlying neuropathology among the PET scans (Table 1).

\section{MR imaging of mice}

A brain MR scan was performed on all tg and ctl mice within 0 to 6 days after PET scans. Throughout the MR scan, animals were under continuous $1.0 \%$ to $1.8 \%$ isoflurane anesthesia with $2 \mathrm{~L} / \mathrm{min}$ oxygen flow. Eyes were protected with dexpanthenol ointment. Hypothermia was prevented with a heat storing gel pack (ColdHot, 3 M, Saint Paul, MN, USA) preheated in a microwave oven.

We acquired $\mathrm{T} 1$ weighted brain images using a 3D turbo gradient echo (3D-TFE) sequence with an inversion pre-pulse (TR: $12 \mathrm{~ms}$, TE: $3.9 \mathrm{~ms}$, TI: $800 \mathrm{~ms}$, TFE factor: 120 , flip angle: $8^{\circ}$, NSA: 12 , acquired matrix $\mathrm{M} \times$ P: $248 \times 120$, partitions: 60 , FOV: $64 \times 32 \times 16 \mathrm{~mm}$, resolution: $0.26 \times 0.27 \times 0.26 \mathrm{~mm}$, reconstructed resolution: $0.13 \times 0.13 \times 0.13 \mathrm{~mm}$ ) on a Philips Achieva $1.5 \mathrm{~T}$ clinical 
Table 1 Scanning regimen of $\left[{ }^{11} \mathrm{C}\right] \mathrm{PiB},\left[{ }^{18} \mathrm{~F}\right] \mathrm{FIBT}$, and $\left[{ }^{18} \mathrm{~F}\right]$ florbetaben

\begin{tabular}{|c|c|c|c|c|c|c|c|c|c|}
\hline Group & Number & Tracer 1 & $\begin{array}{l}\text { Injected dose } \\
\text { (MBq) }\end{array}$ & $\begin{array}{l}\Delta t \text { to next scan } \\
\text { (days) }\end{array}$ & Tracer 2 & $\begin{array}{l}\text { Injected dose } \\
(\mathrm{MBq})\end{array}$ & $\begin{array}{l}\Delta t \text { to next scan } \\
\text { (days) }\end{array}$ & Tracer 3 & $\begin{array}{l}\text { Injected } \\
\text { dose }(\mathrm{MBq})\end{array}$ \\
\hline \multirow[t]{4}{*}{ APP/PS1 } & 1 & Florbetaben & 12.2 & 5 & FIBT & 9.4 & 3 & $\mathrm{PiB}$ & 8.9 \\
\hline & 2 & Florbetaben & 8.9 & 5 & FIBT & 6.6 & 3 & $\mathrm{PiB}$ & 10.7 \\
\hline & 3 & Florbetaben & 9.2 & 13 & FIBT & 16.3 & 3 & $\mathrm{PiB}$ & 19.5 \\
\hline & 4 & Florbetaben & 13.4 & 13 & FIBT & 13.0 & 3 & $\mathrm{PiB}$ & 16.7 \\
\hline \multirow[t]{3}{*}{$\mathrm{Ctl}$} & 1 & Florbetaben & 10.2 & 5 & FIBT & 10.6 & 3 & PiB & 14.3 \\
\hline & 2 & Florbetaben & 7.9 & 5 & FIBT & 8.0 & 3 & $\mathrm{PiB}$ & 12.5 \\
\hline & 3 & Florbetaben & 4.6 & 13 & FIBT & 14.0 & 3 & $\mathrm{PiB}$ & 18.4 \\
\hline
\end{tabular}

MRI system with a 23-mm microscopy coil. Acquisition time was $46 \mathrm{~min} 11 \mathrm{~s}$.

\section{Mouse PET and MRI}

Based on our experience, variance of macroscopic brain anatomy is very low across mice with the same genetic background. Therefore, the creation of a MRI template was done by manual co-registration of all MR images based on prominent brain structures and the overall cortical contour and calculation of a mean image (Pmod 3.3, Pmod Technologies, Zurich, Switzerland). Structures outside of the brain were not considered in the manual co-registration process. Two major volume-of-interests (VOIs) were defined on the MRI template, one comprising the full cortex including hippocampus, the other comprising the full cerebellum. The same VOIs were then used for reading out co-registered PET data of a mean image of the final $10 \mathrm{~min}$ of the scan (minute 36 to 45$)$. The VOIs were chosen based on previous findings in a voxel-based analysis of cerebral $\mathrm{PiB}$ uptake and its correlation with the underlying $A \beta$ pathology in this mouse model [41]. PET data was normalized and corrected for decay and dead time. The images were reconstructed by means of filtered back-projection (FBP), using a ramp filter with a cutoff at the Nyquist frequency into 45 frames $(45 \times 60 \mathrm{~s})$. The image volume consisted of $128 \times 128 \times 159$ voxels, each of a size of $0.78 \times 0.78 \times$ $0.80 \mathrm{~mm}$. The PET images were manually co-registered with the MRI template. This was done by using the wash-in phase of the tracer to identify the brain contour for alignment with the MRI template. We scaled the PET images to percentage of injected dose per cubic centimeter. We then applied these VOIs to the coregistered PET images and exported the VOI values to Microsoft Excel 2010 in order to calculate cortex + hippocampus-to-cerebellum ratios (further referred to as PET ratios).

We tested the $\mathrm{tg} / \mathrm{ctl}$ ratios for significance. First, we performed a one-way ANOVA between the three groups showing significance. Post hoc Bonferroni corrected $t$-tests thresholded at $p<0.05$ revealed that the significant difference is due to group differences between $\mathrm{PiB}$ and florbetaben and FIBT and florbetaben.

\section{Brain dissection and tissue section preparation}

Immediately after the third PET scan, each animal was sacrificed per cervical dislocation. The skull was dissected and opened mid-sagittally with fine scissors. The brain was carefully removed, halved in the left and right hemisphere and frozen with fine crushed dry ice and stored in a refrigerator at $-80^{\circ} \mathrm{C}$. For histological staining, the right hemisphere of each animal was thawed, para-sagittal halved and paraffinated. The resulting paraffin blocks were then cut with a thickness of $5 \mu \mathrm{m}$ and mounted 3 sections per glass slide.

\section{Thioflavin S staining and microscopy}

Before staining, the sections were deparaffinated and rehydrated. The sections were then incubated in a $1 \%$ (1 g per $100 \mathrm{ml}$ water) solution of Thioflavin S (TfS) (T1892, Sigma-Aldrich, St. Louis, MI, USA) for $30 \mathrm{~min}$. The sections were then washed with water three times for $2 \mathrm{~min}$, 80\% ethanol for $6 \mathrm{~min}$, washed again with water and cover slip mounted with VectaShield as mounting medium (H-1500 with DAPI, Vector Laboratories Inc., Burlingame, CA, USA). The slides were stored at $4^{\circ} \mathrm{C}$ until microscopic image acquisition. Digital images were acquired with an automated whole-slidescanner (Mirax Scan, Carl Zeiss MicroImaging $\mathrm{GmbH}$, Jena, Germany) using filter sets for DAPI, GFP, and Texas Red. The DAPI (contained in the mounting medium) fluorescence was used by the scanner to set the optical focus, GFP contained the specific signal of Thioflavin S, and Texas Red delivered unspecific fluorescence such as tissue auto-fluorescence. Images were preprocessed with Photoshop CS4 in order to define (bluechannel) the cortex and hippocampus as regions of interest for plaque load analysis.

\section{Histological plaque load analysis}

To measure the relative plaque load in a region of interest (ROI) of each section, we used the Acapella ${ }^{\mathrm{TM}}$ 
Table 2 Log $D_{\text {oct/PBS }}$ values of tested compounds (mean $\pm S D ; N=6$ )

\begin{tabular}{llll}
\hline Tracer & {$\left[{ }^{11} \mathrm{C}\right]$ PiB } & {$\left[{ }^{18} \mathrm{~F}\right] \mathrm{FIBT}$} & {$\left[{ }^{18} \mathrm{~F}\right] \mathrm{Florbetaben}$} \\
\hline Log $D_{\text {oct/PBS }}$ & $1.50 \pm 0.11$ & $1.92 \pm 0.06$ & $1.58 \pm 0.13$ \\
$p$ & {$\left[{ }^{18} \mathrm{~F}\right] \mathrm{FIBT}>\left[{ }^{11} \mathrm{C}\right] \mathrm{PiB}{ }^{*}$} & {$\left[{ }^{18} \mathrm{~F}\right] \mathrm{FIBT}>\left[{ }^{18} \mathrm{~F}\right]$ florbetaben } & {$\left[{ }^{*} \mathrm{~F}\right] \mathrm{Florbetaben}>\left[{ }^{11} \mathrm{C}\right] \mathrm{PiB}$}
\end{tabular}

*Indicates significant difference at $p<0.05$ in Bonferroni corrected $t$-tests.

analysis software (PerkinElmer Inc., Waltham, MA, USA) applying a special script (developed by Evotec AG, Hamburg, Germany). This script allows quantitative assessment of the relative plaque load (sum of pixels representing plaque signals divided by the sum of all pixels representing the regions of interest). The Texas Red signal was used by Acapella ${ }^{\mathrm{TM}}$ to correct the TfS signal for unspecific fluorescence.

Acapella analysis was verified on each section. Minor detection deficits were tolerated (e.g., failure to detect $<5$ plaques); larger deficits (e.g., failure to detect a group of plaques) lead to exclusion of the particular image. In cases of a large contamination detected as plaquespecific signal (e.g., a tissue fold or dust particle), the region of interest was adjusted. At least 8, maximal 12, sections per tg mouse per staining (respectively 3 to 6 sections per wild-type mouse) were analyzed and mean values of plaque load calculated per animal. Autoradiography (Additional file 1) was performed following procedures already reported [40].

\section{Human $\left[{ }^{11} \mathrm{C}\right] \mathrm{PiB}$ PET}

To enable a comparison to human $\left[{ }^{11} \mathrm{C}\right] \mathrm{PiB}$ PET data, we chose randomly PET datasets from our database of AD patients and healthy controls at TUM. Subjects labelled as AD subjects in this database had a positive PiB scan together with measurable cognitive deficits in neuropsychological testing fulfilling the criteria of dementia. This data had been obtained on a SIEMENS ECAT HR+ scanner (CTI, Knoxville, TN, USA) according to an established and published protocol. Mean global cortical PiB uptake relative to cerebellum expressed as SUVR was calculated in $20 \mathrm{AD}$ patients and in 15 healthy human control subjects using a previously established VOI-based approach $[48,49]$.

\section{Results}

Comparison of fundamental characteristics

$\left[{ }^{18} \mathrm{~F}\right] \mathrm{FIBT},\left[{ }^{18} \mathrm{~F}\right]$ florbetaben, and $\left[{ }^{11} \mathrm{C}\right] \mathrm{PiB}$ were prepared with comparable high quality, purity, and specific activities of $\geq 18 \mathrm{GBq} / \mu \mathrm{mol}$ and directly introduced to a group of four APP/PS1 and three age-matched ctl mice. As lipophilicity is an important functional property of a 'cerebral radiopharmaceutical', log $\mathrm{D}_{\text {oct/PBS }}$ were measured for $\left[{ }^{18} \mathrm{~F}\right]$ FIBT, $\left[{ }^{18} \mathrm{~F}\right]$ florbetaben, and $\left[{ }^{11} \mathrm{C}\right] \mathrm{PiB}$ (Table 2). Lipophilicity of FIBT is slightly higher than those of florbetaben and $\mathrm{PiB}$.

Brain uptake kinetics of florbetaben was measured at 5 and 30 min p.i. in wild-type mice $(N \geq 5)$ and compared to already published data for FIBT and $\mathrm{PiB}$ [25] (Figure 1).

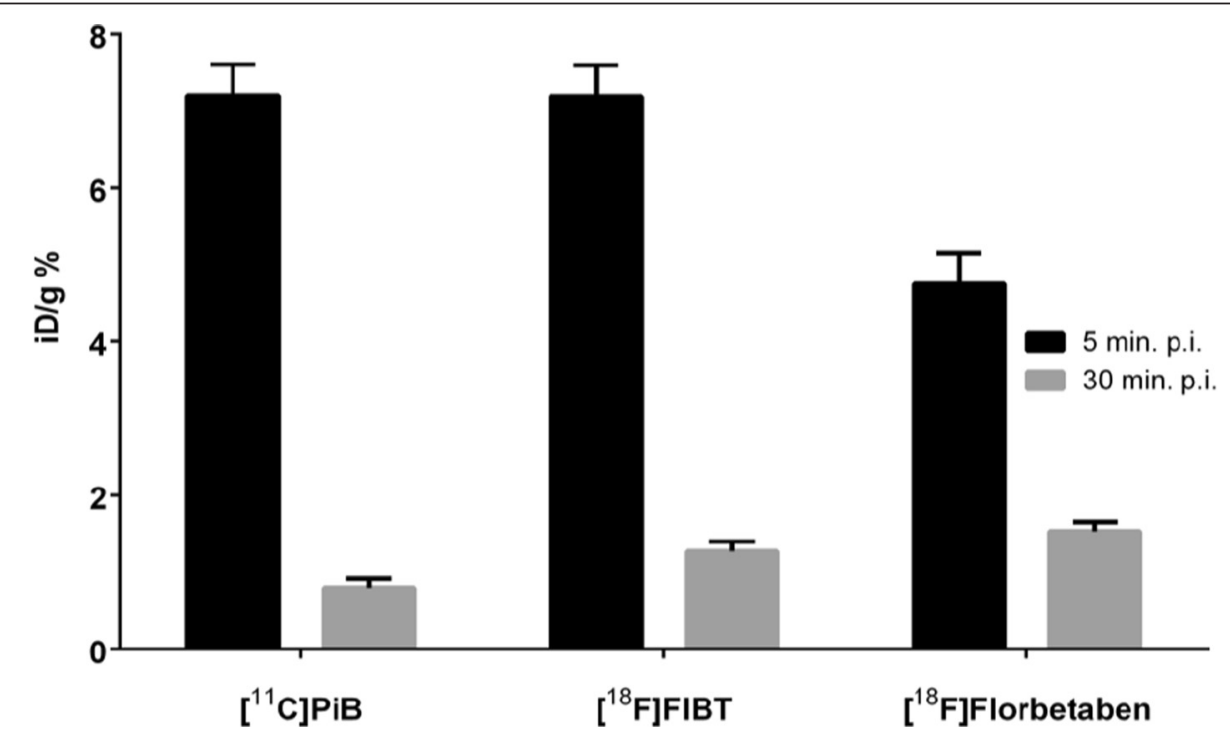

Figure 1 Brain uptake of the tested radiopharmaceuticals. Expressed as percent of injected dose per gram brain weight in male BALB/C mice at 5 and 30 min post injection ( $N=5$ for each tracer at each time point). p.i., post injection. 

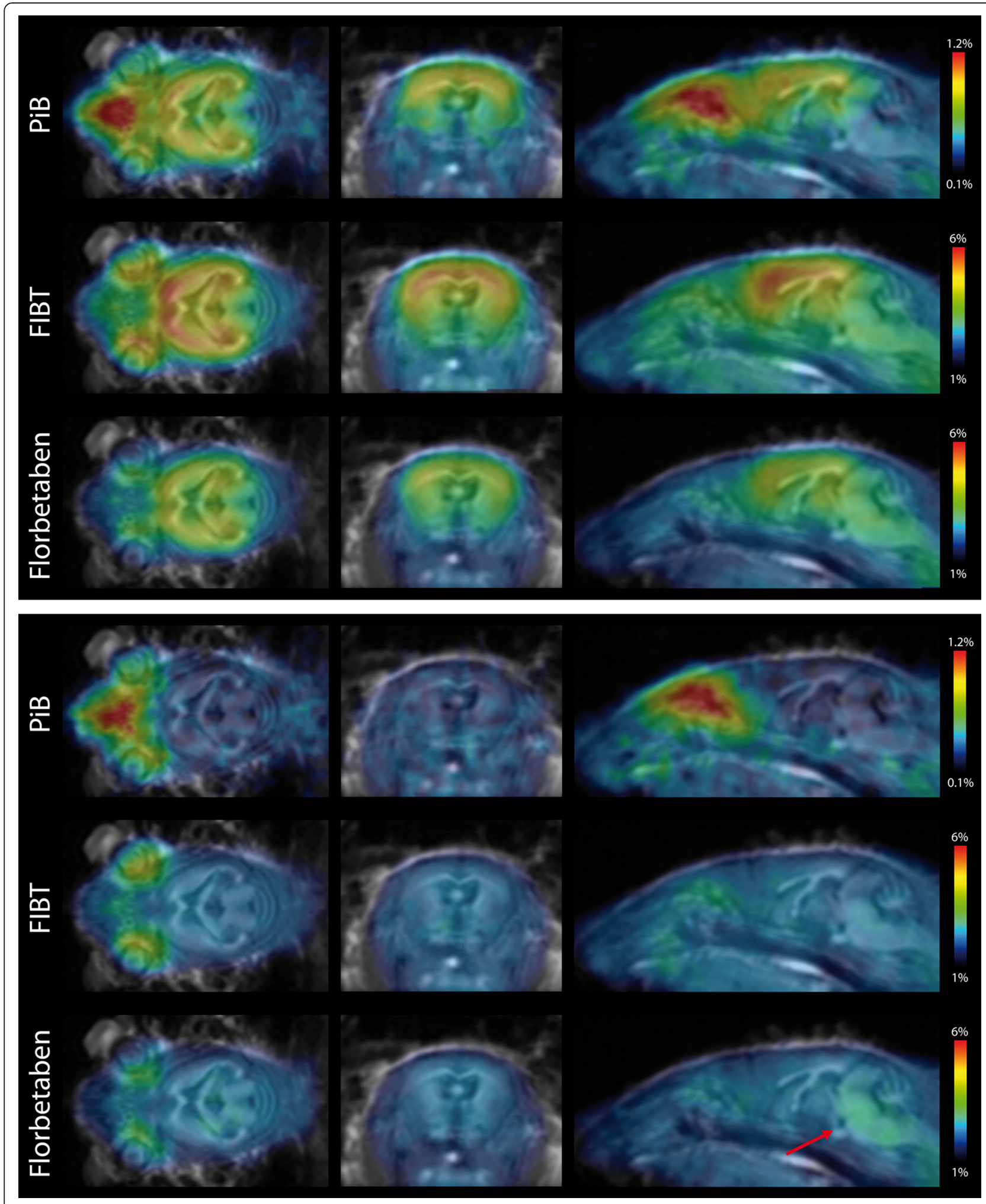

Figure 2 Visual comparison of the three radiopharmaceuticals within the same group of animals. Each row represents a mean image of four 24-month-old APP/PS1 transgenic animals (first three rows), respectively, three age matched wild-type animals (C57BL6/J, last three rows). In vivo PET images in each row represent percentage of injected dose per cubic centimeter (\%ID/cc) averaged over 35 to 45 min post injection, co-registered to a MRI template. From left to right showing axial, sagittal, and coronal views. Red arrow points at higher unspecific uptake of florbetaben compared to FIBT in the brainstem of wild-type animals. 
Intra-individual comparison of FIBT, florbetaben, and PiB in mice

In vivo small animal $\mathrm{PET}$ imaging of the three tracers was compared using a group of four APP/PS1 tg and three ctl mice, co-registered to the MRI template showing axial, sagittal, and coronal views of group-wise mean images (Figure 2). Dynamic PET time activity curves of the cortex-VOI and the cerebellum-VOI for FIBT, florbetaben, and $\mathrm{PiB}$ within identical mice are illustrated in Figure 3. The dynamic PET ratio curves are given in Figure 4, where tg and ctl mice showed significant differences in PET. $\left[{ }^{11} \mathrm{C}\right] \mathrm{PiB}$ showed slightly lower initial uptake values than both ${ }^{18} \mathrm{~F}$-tracers but considerably different wash-out. More pronounced $\left[{ }^{11} \mathrm{C}\right] \mathrm{PiB}$ washout-out from $\mathrm{A} \beta$ free regions was resulting in the highest target-to-referenceregion ratios. The lower washout of $\left[{ }^{18} \mathrm{~F}\right]$ florbetaben observed in BALB/c mice (Figure 1) was also observed on visual inspection of mean PET images of the control group. Here, a higher tracer retention of $\left[{ }^{18} \mathrm{~F}\right]$ florbetaben compared to $\left[{ }^{18} \mathrm{~F}\right] \mathrm{FIBT}$ was detected in the brainstem (see red arrow in Figure 2). Furthermore, mean PET ratios (SUVR, calculated for time interval 36 to $45 \mathrm{~min}$ ) for the APP/PS1 tg group and the control group as well as their ratio $\mathrm{SUVR}_{\mathrm{tg}} / \mathrm{SUVR}_{\mathrm{ctl}}$ are given in Table 3 . Among the three tracers, $\left[{ }^{11} \mathrm{C}\right] \mathrm{PiB}$ showed significantly higher unspecific nasal uptake in all cases. As observed for many PET tracers, all three tracers showed nonspecific uptake in the retrobulbar space, likely representing the Harderian gland.

Post mortem plaque load analysis of APP/PS1 and ctl mice Brain sections of the animals were stained with Thioflavin $S$ for the histological quantification of $A \beta$ plaque

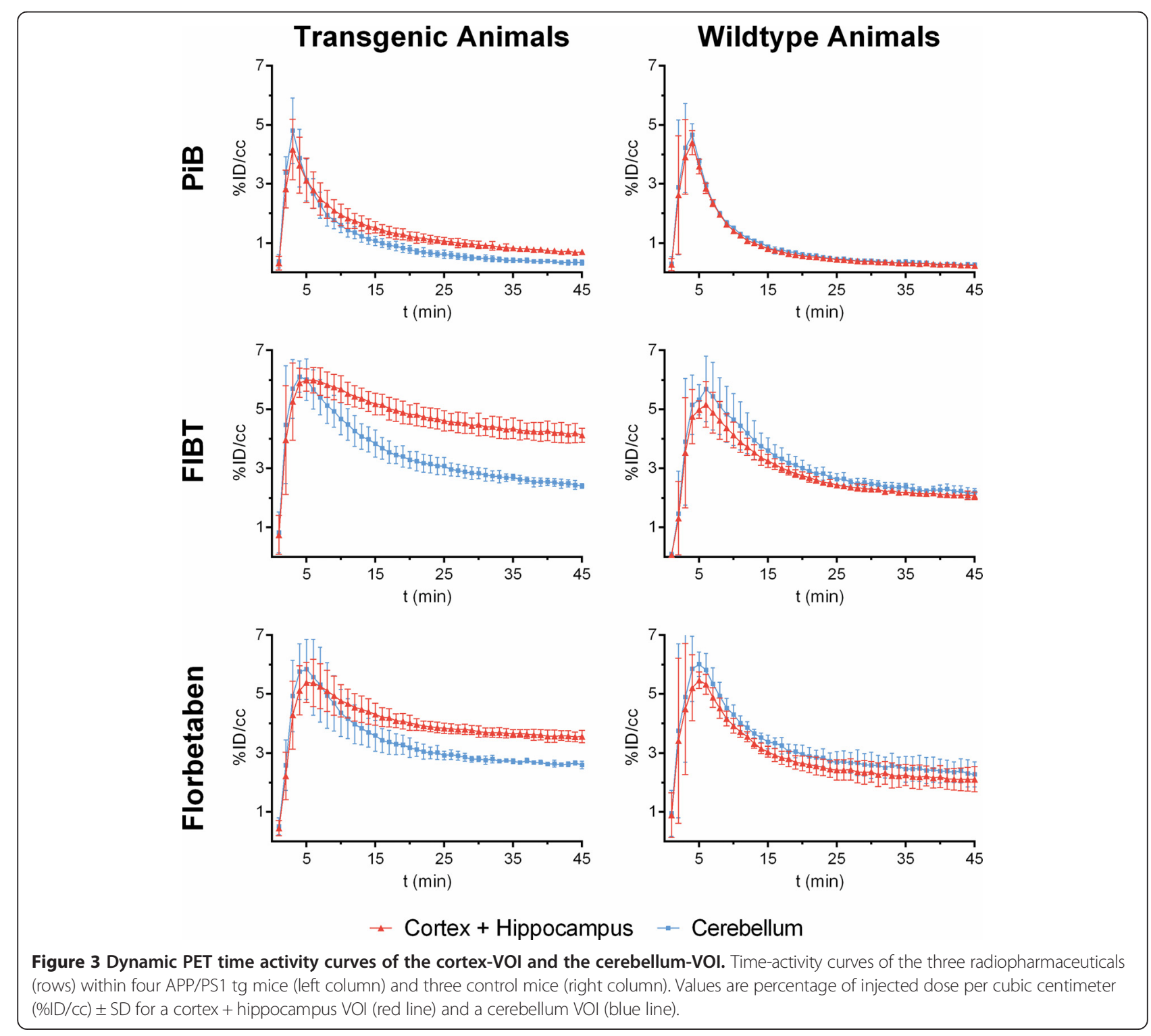




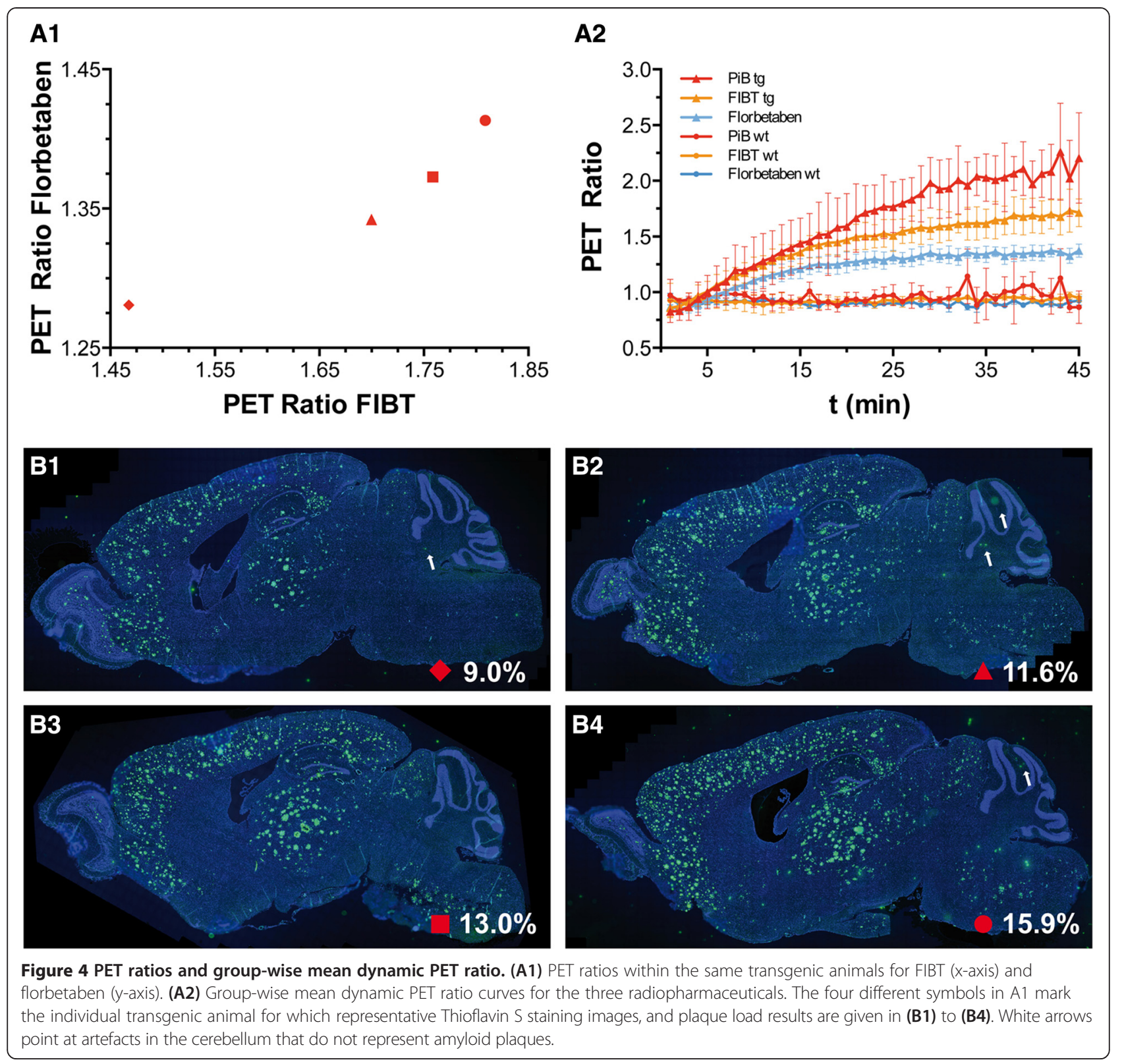

load by applying a computerized image analysis and object recognition algorithm [33]. Significant Thioflavin S positive plaque load was found in each transgenic mouse (Figure 4B1 to B4). Mean false positive plaque load signal was found to be $0.03 \%( \pm 0.01 \mathrm{SD})$ in the control group without amyloid pathology. We found a high linear association between plaque load and PET ratios for all three tracers (Figure 5).

Table 3 Mean PET ratios (SUVR \pm SD) within the four APP/PS1 tg mice and the three control mice (C57BL6/J)

\begin{tabular}{llll}
\hline Tracer & {$\left[{ }^{18} \mathrm{~F}\right] \mathrm{FIBT}$} & {$\left[{ }^{18} \mathrm{~F}\right]$ Florbetaben } & {$\left[{ }^{11} \mathrm{C}\right]$ PiB } \\
\hline APP/PS1 $(\mathrm{N}=4)$ & $1.68 \pm 0.15$ & $1.35 \pm 0.06$ & $2.08 \pm 0.24$ \\
C57BL6/J $(\mathrm{N}=3)$ & $0.95 \pm 0.02$ & $0.90 \pm 0.01$ & $0.99 \pm 0.06$ \\
$\mathrm{tg} / \mathrm{ctl}$ & $1.78 \pm 0.16$ & $1.50 \pm 0.06$ & $2.11 \pm 0.24$ \\
$p$ & {$\left[{ }^{18} \mathrm{~F}\right] \mathrm{FIBT}>\left[{ }^{18} \mathrm{~F}\right]$ florbetaben* } & {$\left[{ }^{11} \mathrm{C}\right] \mathrm{PiB}>\left[{ }^{18} \mathrm{~F}\right]$ florbetaben* } & {$\left[{ }^{11} \mathrm{C}\right] \mathrm{PiB}>\left[{ }^{18} \mathrm{~F}\right] \mathrm{FlBT}$}
\end{tabular}

The last row gives the statistical results of group comparisons of $\mathrm{tg} / \mathrm{ctl}$ ratio values; *indicates significant difference at $p<0.05$ in Bonferroni corrected $t$-tests. 


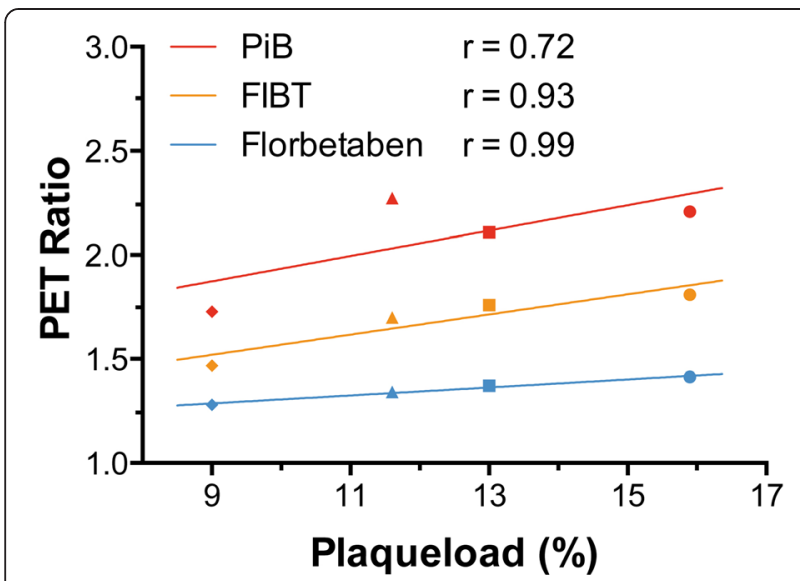

Figure 5 Association of PET signal to Thioflavin S plaque load. Lines represent linear regressions for each tracer. The four different symbols marking the individual transgenic animals are the same as used in Figure 4.

\section{Human in relation to small-animal PiB PET}

To find an expression for the translational value of the preclinical ranking of the three $A \beta$ radiopharmaceuticals, a visual association of preclinical and clinical $\mathrm{PiB}$ data was laid out. Figure 6 illustrates the cortical tracer retention in mice in relation to humans. Analogous to AD patients, there is a strong uptake of $\left[{ }^{11} \mathrm{C}\right] \mathrm{PiB}$ in cortical regions and unspecific low uptake in the cerebellum in transgenic mice. Human controls (HC) and control mice show only unspecific tracer retention across the whole brain.

In vivo $\mathrm{PiB} \mathrm{PET}$ data in $\mathrm{AD}$ patients and human control subjects were also used for calculating SUVR (Table 4). The SUVR values for $\left[{ }^{11} \mathrm{C}\right] \mathrm{PiB}$ of human $\mathrm{AD}$ patients are comparable to the $\left[{ }^{11} \mathrm{C}\right] \mathrm{PiB}$ ratios found in our transgenic cohort (2.01 for $\mathrm{AD}$ patients vs. 2.08 in aged APP/PS1 tg mice).

\section{Discussion}

This study was motivated by the finding that despite a considerable number of ${ }^{18} \mathrm{~F}$-labeled $\mathrm{A} \beta$ tracers that has been described, a final answer to the key question, which of these radiopharmaceuticals shows optimal properties, cannot be given on the basis of existing data. This is mainly due to the inhomogeneity of preclinical characterization methods applied, and further complicated by primarily ethical, but also financial and other practical restrictions of evaluating radiopharmaceuticals head-to-head in the same human subjects. In addition, it appears practically impossible to acquire enough preclinical data to enable a mutual comparison of every possible pair of tracers. As suggested previously [50], this situation could be circumvented by using $\left[{ }^{11} \mathrm{C}\right] \mathrm{PiB}$ as common standard, which is recommendable due to the considerable body of knowledge already gained for this compound. Following this rationale, some of the upcoming ${ }^{18} \mathrm{~F}$-labeled tracers have been compared to $\left[{ }^{11} \mathrm{C}\right] \mathrm{PiB}$ [51,52]. Consequently, $\left[{ }^{11} \mathrm{C}\right] \mathrm{PiB}$ PET results in mice and humans were also implemented in our study as an anchor point for comparison.

One previous paper compared two ${ }^{18} \mathrm{~F}$-labeled $\mathrm{A} \beta$ tracers indirectly via two separate groups of $\mathrm{AD}$ patients with a $\left[{ }^{11} \mathrm{C}\right] \mathrm{PiB}$ scan as link between the two groups [29]. However, this type of indirect comparison requires large cohorts to establish a valid comparison via statistical analysis. In terms of preclinical studies, an intraindividual based comparison of candidate tracers would require a direct correlation of the signal with the individual plaque load of the animal. This is necessary because one has to consider that in small animal models of $\mathrm{AD}$, the inter-subject plaque load is generally not constant, which applies also to our transgenic model [33]. Hence, the most notable advantage of our intra-individual comparison approach is that it allows for drawing meaningful conclusions from smaller sample sizes (cohorts), thus resolving some ethical (cf. triple- $\mathrm{R}$ rule) and economical issues at the same time. Furthermore, a group of transgenic mice can, in principle, be used to compare even more than three $A \beta$ tracers, which might prove a useful means of parallel $A \beta$ tracer evaluation in future studies. Admittedly, a certain drawback of our protocol is that, in principle, absolute quantification of small animal PET signals requires complex image analysis steps. However, by calculating ROI ratios, we chose a straightforward approach, which is frequently applied in clinical as well as preclinical settings, and is widely considered to yield sufficiently precise data to enable meaningful conclusions. The linear association of PET ratios with plaque load for all three tracers in Figure 5 implies that calculating ROI ratios further supports this approach. With the possibility of subsequent ex vivo and histopathological analyses, the advantages of the preclinical approach presented here go far beyond merely circumventing challenges, such as ethical implications of repetitive scans in clinical studies.

We compared $\left[{ }^{18} \mathrm{~F}\right] \mathrm{FIBT}$ with $\left[{ }^{18} \mathrm{~F}\right]$ florbetaben and $\left[{ }^{11} \mathrm{C}\right] \mathrm{PiB}$ using small animal PET in aged transgenic APP/PS1 and control mice. The direct head-to-head PET comparison was supplemented by semi-automated histological plaque load analyses, using the brain material from the animals previously subjected to PET, and by ex vivo brain uptake kinetic analyses in a separate group of wild-type BALB/c mice. Pharmacokinetics of $\left[{ }^{18} \mathrm{~F}\right] \mathrm{FIBT}$ was superior to $\left[{ }^{18} \mathrm{~F}\right]$ florbetaben which also resulted in better PET ratios $(1.68 \pm 0.15$ versus $1.35 \pm$ $0.06)$ in transgenic mice. However, PET ratios of both tracers correlated equally well with amyloid pathology.

Sufficient uptake in the brain and rapid wash-out of unbound tracer are important determinants of potential 

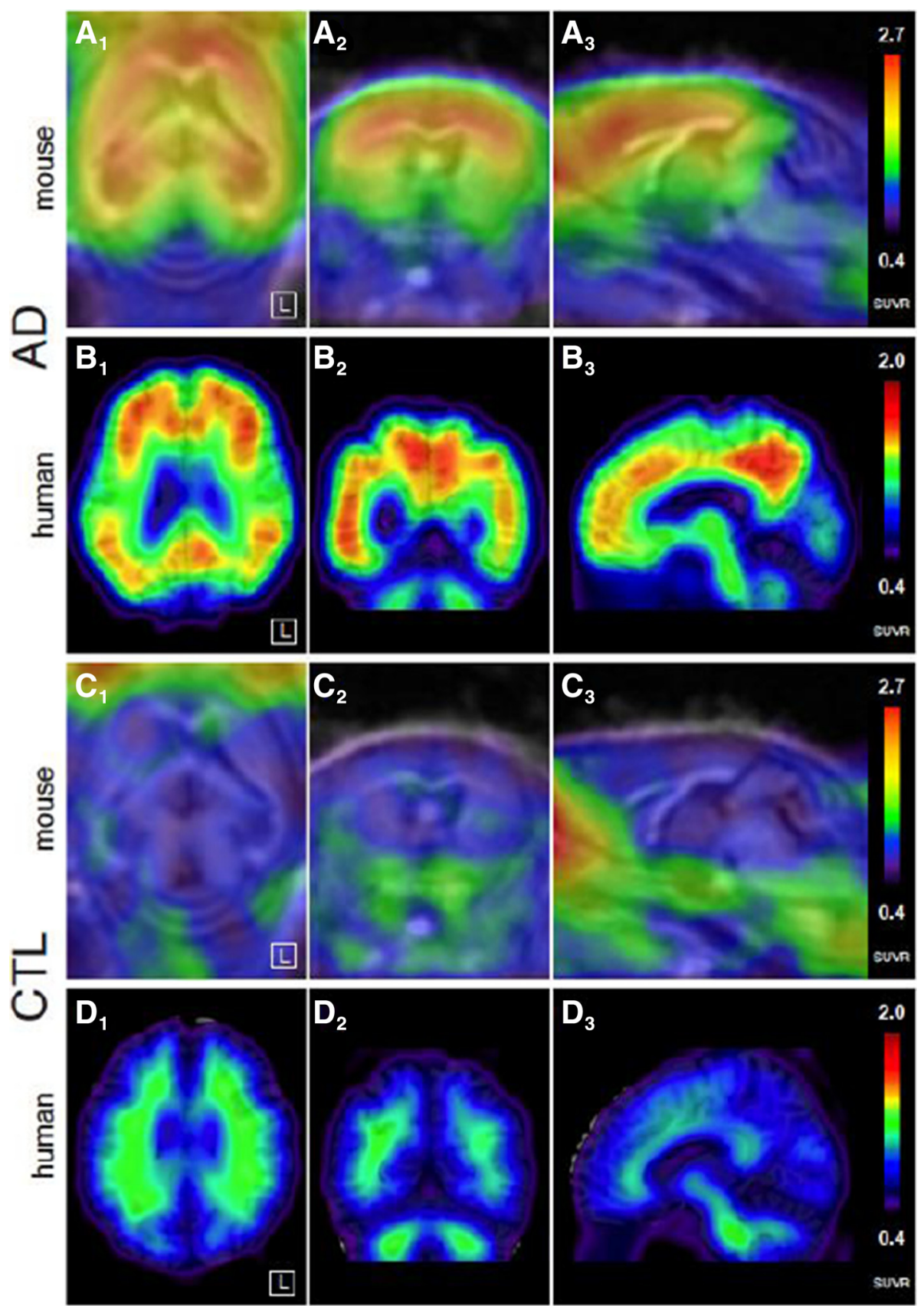

Figure 6 Direct visual comparison of PiB PET in mice and human. Image is showing from left to right axial, coronal, and sagittal views. Mouse images represent a mean image of the four APP/PS1 tg mice and the three control mice, respectively. Human images are from a representative $A D$ patient and healthy control subject, respectively.

Table 4 Human in relation to mouse PET with [ $\left.{ }^{11} \mathrm{C}\right] \mathrm{PiB}$

\begin{tabular}{lll}
\hline & Human & Mouse \\
\hline $\mathrm{AD}$ & $2.01 \pm 0.29$ & $2.08 \pm 0.24$ \\
Controls & $1.22 \pm 0.12$ & $0.99 \pm 0.06$ \\
$\mathrm{AD} / \mathrm{ctl}$ & $1.65 \pm 0.41$ & $2.11 \pm 0.24$ \\
\hline
\end{tabular}

Global cortex/cerebellum ratio (expressed as SUVR) in the human AD group ( $N$ $=20)$ and the HC group $(N=15)$ vs. four APP/PS1 tg mice and three control mice. signal strength and sensitivity of a tracer. These pharmacokinetic properties are commonly assessed by post mortem determination of brain uptake kinetic analyses in healthy animals. At first glance, chemical properties of both ${ }^{18}$ F-labeled tracers meet the requirements for sufficient permeation of the blood-brain barrier, such as low molecular weight and medium lipophilicity [7]. However, we noted a lower initial uptake and higher tracer 
retention at $30 \mathrm{~min}$ p.i. of $\left[{ }^{18} \mathrm{~F}\right]$ florbetaben compared to $\left[{ }^{18} \mathrm{~F}\right] \mathrm{FIBT}$ in animals without $\mathrm{A} \beta$ pathology (BALB/c mice). Higher initial uptake could be attributed to the slightly lower lipophilicity of $\left[{ }^{18} \mathrm{~F}\right]$ florbetaben $(\log D=$ $1.58 \pm 0.13)$ compared to $\left[{ }^{18} \mathrm{~F}\right] \mathrm{FIBT}(\log D=1.92 \pm 0.06)$ $[53,54]$ but might also be related to presence of hydrogen bond donors and acceptors as well as a higher percentage of polar surface area. Higher retention of $\left[{ }^{18} \mathrm{~F}\right]$ florbetaben is likely due to a higher degree of unspecific binding. Hence, the low amount of unspecific retention of $\left[{ }^{18} \mathrm{~F}\right] \mathrm{FIBT}$ represents a substantial improvement, because compared to $\left[{ }^{11} \mathrm{C}\right] \mathrm{PiB}$, most ${ }^{18} \mathrm{~F}$-labeled $\mathrm{AD}$ tracers in advanced clinical trials show a higher tendency towards unspecific binding to the white matter in humans [52,55].

Comparison of PET images of $\mathrm{AD}$ and control mice indicated higher unspecific binding of $\left[{ }^{18} \mathrm{~F}\right]$ florbetaben compared to $\left[{ }^{18} \mathrm{~F}\right] \mathrm{FIBT}$, especially in subcortical regions (red arrow in Figure 2), which is equivalent to a higher $A \beta$ sensitivity of the latter. This might pose an important advantage with respect to the potential role of $A \beta$ PET imaging in the pre-symptomatic phase of the disease [56], which is considered to begin several years before symptom onset (accumulation of pathological aggregates), and is likely the favorable time window for antiamyloid interventions [57].

Apart from pharmacokinetic properties and specificity of binding, $A \beta$ affinity and selectivity determines the quality of a tracer. In a competitive binding assay versus $\left[{ }^{3} \mathrm{H}\right] \mathrm{PiB}$, FIBT showed high affinity to $\mathrm{A} \beta$ aggregates $\left(K_{\mathrm{i}}=2.1 \pm 0.8 \mathrm{nM}\right)$ [25]. Furthermore, in vitro determination of binding affinities to $A \beta$ aggregates, using post mortem $\mathrm{AD}$ brain homogenates, suggest a higher A $\beta$ affinity of $\left[{ }^{18} \mathrm{~F}\right]$ FIBT $\left(K_{\mathrm{d}}=0.7 \pm 0.2 \mathrm{nM}[28]\right)$ than $\left[{ }^{18} \mathrm{~F}\right]$ florbetaben $\left(K_{\mathrm{d}}=6.70 \pm 0.30 \mathrm{nM},[16]\right)$. These results are nicely corroborated by our in vivo data, as we found higher tracer retention for $\left[{ }^{18} \mathrm{~F}\right] \mathrm{FIBT}$ than $\left[{ }^{18} \mathrm{~F}\right]$ florbetaben in $\mathrm{A} \beta$-rich brain regions of APP/PS1 transgenic mice (Figure 4A2). Since specific binding of $\mathrm{PiB}$ to $\mathrm{A} \beta$ in this mouse model was demonstrated previously by in vitro, ex vivo, and in vivo experiments [40], we conclude that higher retention of $\left[{ }^{18} \mathrm{~F}\right] \mathrm{FIBT}$ in target regions corresponds to improved specificity of binding in vivo as well.

Furthermore, it was shown earlier that the cortex-tocerebellum ratios of $\mathrm{PiB}$ correlate well with the absolute amount of $A \beta$ in the cortex, the place where most of the $\mathrm{A} \beta$ deposits are found [41]. Ratios of PiB in APP/PS1 transgenic mice closely resembled the ratios measured in our cohort of $\mathrm{AD}$ patients, further supporting the notion that our transgenic mouse model is suitable for PET imaging studies of $A \beta$ pathology. Being aware that results from small animal experiments can usually not be directly translated to a clinical setting, we nevertheless hold the view that clinical properties of other tracers evaluated in the same setting could be predicted with certain accuracy. Thus, we assume that FIBT could perform very well in human as a promising diagnostic $A \beta$ radiopharmaceutical and robust imaging tool with potential to become an earlier AD biomarker.

\section{Conclusions}

With an increasing number of ${ }^{18} \mathrm{~F}$-labeled $\mathrm{A} \beta$ tracers, comparative studies are of high value for providing diagnostic and prognostic information and feasibility rankings. Despite general problems of transferability of preclinical results to clinical settings, our study suggests that small animal PET imaging using a suitable animal model combined with ex vivo and in vitro experiments is a practicable approach for comparative $A \beta$ tracer assessment. Overall, all assessed tracers allowed high-contrast imaging of $A \beta$ deposits in transgenic models of AD. Our results indicate a superior performance of $\left[{ }^{18} \mathrm{~F}\right] \mathrm{FIBT}$ relative to $\left[{ }^{18} \mathrm{~F}\right]$ florbetaben regarding pharmacokinetics and specific binding affinity towards $A \beta$ aggregates. These results support further evaluation of $\left[{ }^{18} \mathrm{~F}\right] \mathrm{FIBT}$ in human investigations.

\section{Additional file}

Additional file 1: Ex vivo confirmation study. Figure S1. $\left[{ }^{18} \mathrm{~F}\right] \mathrm{FIBT}$ and $\left[{ }^{18} \mathrm{~F}\right]$ florbetaben autoradiography and cortex/cerebellum uptake ratio $(n \geq 3)$.

\section{Competing interests}

The authors declare that they have no competing interests. AD has received speaker consulting/speaker bureau jobs fees from Avid/Lilly, GE, and Piramal.

\section{Authors' contributions}

$\mathrm{BHY}$ coordinated the study and participated in the study design, carried out the experiments, the analysis of radiochemical synthesis, biological evaluations, and drafted the manuscript. BvR participated in study design and carried out experiments and analysis and drafted the manuscript. DS participated in PMOD analysis of $\mu$ PET data and helped to draft the manuscript. AM participated in the study design and in the analysis of comparison of PIB PET in mice and human and helped to draft the manuscript. AD, TG, and SF participated in human PET study design and analysis and helped to draft the manuscript. MS, GH, AD, and HJW participated in the study design, and helped to draft the manuscript. All authors read and approved the final manuscript.

\section{Authors' information}

$\mathrm{BHY}$ is a senior radiopharmaceutical chemist, Ph.D. of organic chemistry, Department of Pharmaceutical Radiochemistry, Technische Universität München. BvR is a resident of neurology and Ph.D. of medical life science at INM-3, Research Centre Jülich. DS is a student of medicine at Technische Universität München. AM is a postdoctoral fellow in nuclear medicine, Ph. D. of medical life science, Technische Universität München. MS is a professor and head of the Department of Nuclear Medicine, Technische Universität München. TG is a senior clinic consultant in psychiatry at the Department of Psychiatry and Psychotherapy, Technische Universität München. GH is a research director at PET Centre Oslo, Ph.D. of radiochemistry, and SF is a senior clinic consultant in nuclear medicine at the Department of Nuclear Medicine, Technische Universität München. AD is a professor and head of the Department of Nuclear Medicine, University Hospital Cologne. HJW is a professor and head of the Department of Pharmaceutical Radiochemistry, Technische Universität München, Munich, Germany. 


\section{Acknowledgements}

The authors thank Heinz von der Kammer, Evotec AG Hamburg and Michael Schoor, Taconic Biosciences GmbH for provision of the APP/PS1 mice; Michael Herz and Reinhold Klitsch for producing radioisotopes; and Sybille Reder, Monika Beschorner, Andrea Alke, and Katharina McGuire for excellent support by animal experimental. We also acknowledge Johannes Notni for prompt proofreading of this manuscript. This work was supported by DFG HE 4560/1-3 and DFG RTG 1373, DFG DR 445/3-1, 4-1, ERC Grant MUMI - No. 294582 and the Research Training Group 1373.

\section{Author details}

${ }^{1}$ Department of Pharmaceutical Radiochemistry, Technische Universität München, Walther-Meißner-Str. 3, 85748 Garching, Germany. ${ }^{2}$ Department of Nuclear Medicine, Technische Universität München, Ismaninger Straße 22, 81675 Munich, Germany. ${ }^{3}$ Department of Psychiatry and Psychotherapy, Technische Universität München, Ismaninger Straße 22, 81675 Munich, Germany. ${ }^{4}$ Institute of Neuroscience and Medicine (INM-3), Research Centre Jülich, Wilhelm-Johnen-Straße, 52428 Jülich, Germany. ${ }^{5}$ Department of Nuclear Medicine, University of Cologne, Kerpener Straße 62, 50937 Cologne, Germany.

\section{Received: 7 November 2014 Accepted: 22 February 2015} Published online: 28 March 2015

\section{References}

1. Watanabe H, Ono M, Kimura H, Kagawa S, Nishii R, Fuchigami T, et al. A dual fluorinated and iodinated radiotracer for PET and SPECT imaging of beta-amyloid plaques in the brain. Bioorg Med Chem Lett. 2011;21(21):6519-22. doi:10.1016/j.bmcl.2011.08.063.

2. Kung MP, Weng CC, Lin KJ, Hsiao IT, Yen TC, Wey SP. Amyloid plaque imaging from IMPY/SPECT to AV-45/PET. Chang Gung Med J. 2012;35(3):211-8.

3. Swahn BM, Sandell J, Pyring D, Bergh M, Jeppsson F, Jureus A, et al. Synthesis and evaluation of pyridylbenzofuran, pyridylbenzothiazole and pyridylbenzoxazole derivatives as (18)F-PET imaging agents for beta-amyloid plaques. Bioorg Med Chem Lett. 2012;22(13):4332-7. doi:10.1016/j. bmcl.2012.05.011.

4. Hardy JA, Higgins GA. Alzheimer's disease: the amyloid cascade hypothesis Science. 1992;256(5054):184-5.

5. Hardy J, Selkoe DJ. The amyloid hypothesis of Alzheimer's disease: progress and problems on the road to therapeutics. Science. 2002;297(5580):353-6. doi:10.1126/science.1072994.

6. Reitz C. Alzheimer's disease and the amyloid cascade hypothesis: a critical review. Int J Alzheimers Dis. 2012;2012:369808. doi:10.1155/2012/369808.

7. Henriksen G, Yousefi BH, Drzezga A, Wester HJ. Development and evaluation of compounds for imaging of beta-amyloid plaque by means of positron emission tomography. Eur J Nucl Med Mol Imaging. 2008;35 Suppl 1:S75-81. doi:10.1007/s00259-007-0705-x.

8. Quigley H, Colloby SJ, O'Brien JT. PET imaging of brain amyloid in dementia: a review. Int J Geriatric Psychiatry. 2011;26(10):991-9. doi:10.1002/gps.2640.

9. Brockschnieder D, Schmitt-Willich H, Heinrich T, Varrone A, Gulyas B, Toth $\mathrm{M}$, et al. Preclinical characterization of a novel class of ${ }^{18} \mathrm{~F}$-labeled PET tracers for amyloid-beta. J Nuclear Med. 2012;53(11):1794-801. doi:10.2967/jnumed.112.104810.

10. Vlassenko AG, Benzinger TL, Morris JC. PET amyloid-beta imaging in preclinical Alzheimer's disease. Biochim Biophys Acta. 2012;1822(3):370-9. doi:10.1016/j.bbadis.2011.11.005.

11. Koole M, Lewis DM, Buckley C, Nelissen N, Vandenbulcke M, Brooks DJ, et al. Whole-body biodistribution and radiation dosimetry of 18 F-GE067: a radioligand for in vivo brain amyloid imaging. J Nucl Med. 2009;50(5):818-22. doi:10.2967/jnumed.

12. Nelissen N, Van Laere K, Thurfjell L, Owenius R, Vandenbulcke M, Koole M, et al Phase 1 study of the Pittsburgh compound B derivative 18 F-flutemetamol in healthy volunteers and patients with probable Alzheimer disease. J Nuclear Med. 2009;50(8):1251-9. doi:10.2967/jnumed.109.063305.

13. Rowe CC, Ackerman U, Browne W, Mulligan R, Pike KL, O'Keefe G, et al. Imaging of amyloid beta in Alzheimer's disease with 18 F-BAY94-9172, a novel PET tracer: proof of mechanism. Lancet Neurol. 2008;7(2):129-35. doi:10.1016/S1474-4422(08)70001-2

14. O'Keefe GJ, Saunder TH, Ng S, Ackerman U, Tochon-Danguy HJ, Chan JG, et al. Radiation dosimetry of beta-amyloid tracers 11C-PiB and 18 F-BAY94-9172.
J Nucl Med: official publication, Soc Nuclear Med. 2009;50(2):309-15. doi:10.2967/jnumed.108.055756.

15. Wang H, Shi H, Yu H, Jiang S, Tang G. Facile and rapid one-step radiosynthesis of [(18)F]BAY94-9172 with a new precursor. Nucl Med Biol. 2011;38(1):121-7. doi:10.1016/j.nucmedbio.2010.06.009.

16. Choi SR, Golding G, Zhuang Z, Zhang W, Lim N, Hefti F, et al. Preclinical properties of 18 F-AV-45: a PET agent for Abeta plaques in the brain. J Nucl Med. 2009;50(11):1887-94. doi:10.2967/jnumed.109.065284.

17. Lin KJ, Hsu WC, Hsiao IT, Wey SP, Jin LW, Skovronsky D, et al. Whole-body biodistribution and brain PET imaging with $\left[{ }^{18} \mathrm{~F}\right] \mathrm{AV}-45$, a novel amyloid imaging agent - a pilot study. Nucl Med Biol. 2010;37(4):497-508. doi:10.1016/j.nucmedbio.2010.02.003.

18. Wong DF, Rosenberg PB, Zhou Y, Kumar A, Raymont V, Ravert HT, et al. In vivo imaging of amyloid deposition in Alzheimer disease using the radioligand ${ }^{18} \mathrm{~F}-\mathrm{AV}-45$ (florbetapir [corrected] F 18). J Nuclear Med. 2010;51(6):913-20. doi:10.2967/jnumed.109.069088.

19. Yao CH, Lin KJ, Weng CC, Hsiao IT, Ting YS, Yen TC, et al. GMP-compliant automated synthesis of [(18)F]AV-45 (Florbetapir F 18) for imaging betaamyloid plaques in human brain. Appl Radiat Isot. 2010;68(12):2293-7. doi:10.1016/j.apradiso.2010.07.001.

20. Carome M, Wolfe S. Florbetapir-PET imaging and postmortem betaamyloid pathology. JAMA. 2011;305(18):1857. author reply -8. doi:10.1001/jama.2011.579.

21. Clark CM, Schneider JA, Bedell BJ, Beach TG, Bilker WB, Mintun MA, et al. Use of florbetapir-PET for imaging beta-amyloid pathology. JAMA. 2011;305(3):275-83. doi:305/3/275 [pii] 10.1001/jama.2010.2008.

22. Lister-James J, Pontecorvo MJ, Clark C, Joshi AD, Mintun MA, Zhang W, et al. Florbetapir f-18: a histopathologically validated Beta-amyloid positron emission tomography imaging agent. Semin Nucl Med. 2011:41(4):300-4. doi:10.1053/j.semnuclmed.2011.03.001.

23. Fleisher AS, Chen K, Liu X, Roontiva A, Thiyyagura P, Ayutyanont N, et al. Using positron emission tomography and florbetapir $F 18$ to image cortical amyloid in patients with mild cognitive impairment or dementia due to Alzheimer disease. Arch Neurol. 2011;68(11):1404-11. do:10.1001/archneurol.2011.150.

24. Okamura N, Yanai K. Florbetapir $\left({ }^{18} \mathrm{~F}\right)$, a PET imaging agent that binds to amyloid plaques for the potential detection of Alzheimer's disease. IDrugs. 2011;13(12):890-9.

25. Yousefi BH, Drzezga A, von Reutern B, Manook A, Schwaiger M, Wester HJ, et al. A novel ${ }^{18}$ F-labeled imidazo[2,1-b]benzothiazole (IBT) for high-contrast PET imaging of $\beta$-amyloid plaques. ACS Med Chem Lett. 2011;2(9):673-7.

26. Cselenyi Z, Jonhagen ME, Forsberg A, Halldin C, Julin P, Schou M, et al. Clinical validation of ${ }^{18} \mathrm{~F}$-AZD4694, an amyloid-beta-specific PET radioligand. J Nuclear Med. 2012;53(3):415-24. doi:10.2967/jnumed.111.094029.

27. Yousefi BH, Manook A, Drzezga A, von Reutern B, Schwaiger M, Wester HJ, et al. Synthesis and evaluation of 11C-labeled imidazo[2,1-b] benzothiazoles (IBTs) as PET tracers for imaging beta-amyloid plaques in Alzheimer's disease. J Med Chem. 2011;54(4):949-56. doi:10.1021/jm101129a.

28. Yousefi BH, Manook A, Grimmer T, Arzberger T, von Reutern B, Henriksen G et al. Characterization and first human investigation of FIBT, a novel fluorinated abeta plaque neuroimaging PET radioligand. ACS Chem Neurosci. 2015. doi:10.1021/cn5001827

29. Landau SM, Thomas BA, Thurfjell L, Schmidt M, Margolin R, Mintun M, et al. Amyloid PET imaging in Alzheimer's disease: a comparison of three radiotracers. Eur J Nucl Med Mol Imaging. 2014;41(7):1398-407. doi:10.1007/s00259-014-2753-3.

30. Mathis CA, Wang Y, Klunk WE. Imaging beta-amyloid plaques and neurofibrillary tangles in the aging human brain. Curr Pharm Des. 2004;10(13):1469-92.

31. Villain N, Chetelat G, Grassiot B, Bourgeat P, Jones G, Ellis KA, et al. Regional dynamics of amyloid-beta deposition in healthy elderly, mild cognitive impairment and Alzheimer's disease: a voxelwise PiB-PET longitudinal study. Brain. 2012;135(Pt 7):2126-39. doi:10.1093/brain/aws125.

32. Gotz J, Ittner LM. Animal models of Alzheimer's disease and frontotemporal dementia. Nat Rev Neurosci. 2008;9(7):532-44. doi:10.1038/nrn2420.

33. Willuweit A, Velden J, Godemann R, Manook A, Jetzek F, Tintrup H, et al. Early-onset and robust amyloid pathology in a new homozygous mouse model of Alzheimer's disease. PLOS ONE. 2009;4(11):e7931. doi:10.1371/journal.pone.0007931.

34. Svedberg MM, Rahman O, Hall H. Preclinical studies of potential amyloid binding PET/SPECT ligands in Alzheimer's disease. Nucl Med Biol. 2012;39 (4):484-501. doi:10.1016/j.nucmedbio.2011.10.007. 
35. Snellman A, Lopez-Picon FR, Rokka J, Salmona M, Forloni G, Scheinin M, et al. Longitudinal amyloid imaging in mouse brain with ${ }^{11} \mathrm{C}$-PIB: comparison of APP23, Tg2576, and APPswe-PS1dE9 mouse models of Alzheimer disease. J Nuclear Med. 2013;54(8):1434-41. doi:10.2967/jnumed.112.110163.

36. Snellman A, Rokka J, Lopez-Picon FR, Eskola O, Wilson I, Farrar G, et al. Pharmacokinetics of ${ }^{18} \mathrm{~F}$ flutemetamol in wild-type rodents and its binding to beta amyloid deposits in a mouse model of Alzheimer's disease. Eur J Nuc Med Mol Imaging. 2012;39(11):1784-95. doi:10.1007/s00259-012-2178-9.

37. Brendel M, Delker A, Rotzer C, Boning G, Carlsen J, Cyran C, et al. Impact of partial volume effect correction on cerebral beta-amyloid imaging in APP-Swe mice using [ $\left.{ }^{18} \mathrm{~F}\right]$-florbetaben PET. Neurolmage. 2013;84C:843-53. doi:10.1016/j.neuroimage.2013.09.017.

38. Rominger A, Brendel M, Burgold S, Keppler K, Baumann K, Xiong G, et al. Longitudinal assessment of cerebral beta-amyloid deposition in mice overexpressing Swedish mutant beta-amyloid precursor protein using ${ }^{18} \mathrm{~F}$-florbetaben PET. J Nuclear Med. 2013;54(7):1127-34 doi:10.2967/jnumed.112.114660.

39. Maeda J, Ji B, Irie T, Tomiyama T, Maruyama M, Okauchi T, et al. Longitudinal, quantitative assessment of amyloid, neuroinflammation, and anti-amyloid treatment in a living mouse model of Alzheimer's disease enabled by positron emission tomography. J Neurosci. 2007;27(41):10957-68. doi:10.1523/JNEUROSCI.0673-07.

40. Yousefi BH, Manook A, von Reutern B, Schwaiger M, Drzezga A, Wester HJ, et al. Development of an improved radioiodinated 2-phenylimidazo[1,2-a]pyridine for non-invasive imaging of amyloid plaques. Medchemcomm. 2012;3(7):775-9. doi:10.1039/C2md20115a.

41. von Reutern B, Grunecker B, Yousefi BH, Henriksen G, Czisch M, Drzezga A. Voxel-based analysis of amyloid-burden measured with $\left[{ }^{11} \mathrm{C}\right] \mathrm{PiB}$ PET in a double transgenic mouse model of Alzheimer's disease. Molecular Imaging Biol. 2013;15(5):576-84. doi:10.1007/s11307-013-0625-z.

42. Villemagne VL, Ong K, Mulligan RS, Holl G, Pejoska S, Jones G, et al. Amyloid imaging with $\left[{ }^{18} \mathrm{~F}\right]$ florbetaben in Alzheimer disease and other dementias. J Nuclear Med. 2011;52(8):1210-7. doi:10.2967/jnumed.111.089730.

43. Patt M, Schildan A, Barthel H, Becker G, Schultze-Mosgau MH, Rohde B, et al. Metabolite analysis of $\left[{ }^{18} \mathrm{~F}\right]$ florbetaben (BAY 94-9172) in human subjects: a substudy within a proof of mechanism clinical trial. J Radioanal Nucl Chem. 2010;284:557-62.

44. Barthel H, Gertz HJ, Dresel S, Peters O, Bartenstein P, Buerger K, et al. Cerebral amyloid-beta PET with [ $\left.{ }^{18} \mathrm{~F}\right]$ florbetaben in patients with Alzheimer's disease and healthy controls: a multicentre phase 2 diagnostic study. Lancet Neurol. 2011;10(5):424-35. doi:10.1016/S1474-4422(11)70077-1.

45. Henriksen G, Hauser Al, Westwell AD, Yousefi BH, Schwaiger M, Drzezga A, et al. Metabolically stabilized benzothiazoles for imaging of amyloid plaques. J Med Chem. 2007;50(6):1087-9. doi:10.1021/jm061466g.

46. Grimmer $\mathrm{T}$, Tholen $\mathrm{S}$, Yousefi $\mathrm{BH}$, Alexopoulos $\mathrm{P}$, Forschler $\mathrm{A}$, Forstl $\mathrm{H}$, et al. Progression of cerebral amyloid load is associated with the apolipoprotein $E$ epsilon 4 genotype in Alzheimer's disease. Biol Psychiatry. 2010;68(10):879-84. doi:10.1016/j.biopsych.2010.05.013.

47. Forster S, Grimmer T, Miederer I, Henriksen G, Yousefi BH, Graner P et al. Regional expansion of hypometabolism in Alzheimer's disease follows amyloid deposition with temporal delay. Biol Psychiatry. 2011. doi:10.1016/j.biopsych.2011.04.023

48. Forster S, Grimmer T, Miederer I, Henriksen G, Yousefi BH, Graner P, et al. Regional expansion of hypometabolism in Alzheimer's disease follows amyloid deposition with temporal delay. Biol Psychiatry. 2012;71(9):792-7. doi:10.1016/j.biopsych.2011.04.023.

49. Forster S, Yousefi BH, Wester HJ, Klupp E, Rominger A, Forstl H, et al. Quantitative longitudinal interrelationships between brain metabolism and amyloid deposition during a 2-year follow-up in patients with early Alzheimer's disease. Eur J Nucl Med Mol Imaging. 2012;39(12):1927-36. doi:10.1007/s00259-012-2230-9.

50. Klunk WE, Mathis CA. The future of amyloid-beta imaging: a tale of radionuclides and tracer proliferation. Curr Opin Neurol. 2008;21(6):683-7. doi:10.1097/WCO.0b013e3283168e1a.

51. Serdons K, Verduyckt T, Vanderghinste $D$, Cleynhens J, Borghgraef $P$, Vermaelen $\mathrm{P}$, et al. Synthesis of ${ }^{18} \mathrm{~F}$-labelled 2-(4'-fluorophenyl)-1,3-benzothiazole and evaluation as amyloid imaging agent in comparison with $\left[{ }^{11} \mathrm{C}\right] \mathrm{PiB}$. Bioorg Med Chem Lett. 2009;19(3):602-5. doi:10.1016/j.bmcl.2008.12.069.

52. Rowe CC, Pejoska S, Mulligan RS, Jones G, Chan JG, Svensson S, et al. Head-to-head comparison of ${ }^{11} \mathrm{C}-\mathrm{PiB}$ and ${ }^{18} \mathrm{~F}-\mathrm{AZD} 4694$ (NAV4694) for beta-amyloid imaging in aging and dementia. J Nuclear Med. 2013;54(6):880-6. doi:10.2967/jnumed.112.114785.

53. Laruelle M, Slifstein M, Huang Y. Relationships between radiotrace properties and image quality in molecular imaging of the brain with positron emission tomography. Molecular imaging Biol. 2003;5(6):363-75.

54. Waterhouse RN. Determination of lipophilicity and its use as a predictor of blood-brain barrier penetration of molecular imaging agents. Molecular Imaging Biol. 2003;5(6):376-89.

55. Rowe CC, Villemagne VL. Amyloid imaging with PET in early Alzheimer disease diagnosis. Medl Clin North Am. 2013;97(3):377-98. doi:10.1016/j.mena.2012.12.017

56. Jack Jr CR, Holtzman DM. Biomarker modeling of Alzheimer's disease. Neuron. 2013:80(6):1347-58. doi:10.1016/..neuron.2013.12.003.

57. Panza F, Solfrizzi V, Imbimbo BP, Tortelli R, Santamato A, Logroscino G. Amyloid-based immunotherapy for Alzheimer's disease in the time of prevention trials: the way forward. Expert Rev Clin Immunol. 2014;10(3):405-19. doi:10.1586/1744666X.2014.883921.

\section{Submit your manuscript to a SpringerOpen ${ }^{\odot}$ journal and benefit from:}

- Convenient online submission

- Rigorous peer review

- Immediate publication on acceptance

- Open access: articles freely available online

- High visibility within the field

- Retaining the copyright to your article

Submit your next manuscript at $>$ springeropen.com 